\title{
Agent Based Modelling as a Decision Support System for Shadow Accounting Decision Support Systems
}

\author{
Thomas Chesney ${ }^{\mathrm{a}, *}$, Stefan Gold ${ }^{\mathrm{b}}$, Alexander Trautrims ${ }^{\mathrm{a}}$ \\ ${ }^{a}$ Nottingham University Business School, University of Nottingham, UK \\ ${ }^{b}$ Faculty of Economics and Management, University of Kassel, Germany
}

\begin{abstract}
We propose the use of agent based modelling to create a shadow account, that is, a secondary account of a business which is used to audit or verify the primary account. Such a model could be used to test the claims of industries and businesses. For example, the model could determine whether a business is generating enough funds to pay minimum wage. Parameters in the model can be set by observation or a range of values can be tested to determine points at which enough revenue could be generated. We illustrate the potential of agent based modelling as a tool for shadow accounting with a case study of a car wash business.
\end{abstract}

Keywords: minimum wage, social compliance, auditing, accountability

This paper has been published in Decision Support Systems

DOI: 10.1016/j.dss.2017.01.004

Link: http://dx.doi.org/10.1016/j.dss.2017.01.004

\section{Introduction}

Stakeholders demand comprehensive and reliable disclosure from businesses on their activities, their performance, and the impacts that they have on society and

\footnotetext{
ॠAuthors are listed in alphabetical order.

${ }^{*}$ Corresponding author.

Email addresses: thomas. chesney@nottingham.ac.uk (Thomas Chesney), gold@uni-kassel.de (Stefan Gold), alexander.trautrims@nottingham.ac.uk (Alexander Trautrims)
} 
the environment. Businesses respond to this pressure by engaging in communication with their stakeholders through annual reports, sustainability statements, social media posts and personal communications (Owen et al., 2001). Such communications are presented as fact but have been found to overemphasise good news and downplay bad news, or to omit negative messages altogether (GuillamonSaorin et al., 2012; Merkl-Davies et al., 2011; Reimsbach and Hahn, 2015). The discrepancy between these corporate narratives and actual corporate performance has been termed the "reporting-performance portrayal gap" (Adams, 2004, p.731). Despite external assurance issued by commercial auditors (Comyns et al., 2013) this gap has not been substantially reduced (Knebel and Seele, 2015; Junior et al., 2014).

Stakeholders face major difficulties in verifying and evaluating the information provided by businesses yet need high quality information to empower them to act as watchdogs against companies who might jeopardise their interests and the interests of society at large (Heikkurinen and Ketola, 2012; Dingwerth and Eichinger, 2010). This watchdog capacity hinges crucially on access to independent information for complementing, balancing and verifying corporate accounts (O'Sullivan and O'Dwyer, 2009). Sources of independent information have been conceptualized as shadow accounts, sometimes called counter accounts or anti-accounts (Gallhofer et al., 2006; Boiral, 2013; Rodrigue, 2014). Although they can play a decisive role in revealing conflicts and contradictions in corporate communications that may destabilise the status-quo and spur change (Adams and Whelan, 2009), shadow accounts have largely suffered from being unsystematic, partial, selective and unreliable (Gray et al., 2014). One may generally assume a negative correlation between the independence of parties issuing shadow accounts and their access to internal business information and this hampers the validity of their conclusions.

Hence there is a need for decision tools that can help external stakeholders to verify accounts provided by business, thus emancipating stakeholders from corporate tutelage by enhancing their capacity to evaluate corporate disclosures and corporate action (Spence, 2009). Some approaches have already been developed for the area of financial accounting. These facilitate the evaluation of corporate disclosure - verbal and written - in terms of credibility. Nonetheless, there is a dearth of tools that enable external stakeholders to evaluate corporate action beyond financial accounting. We fill this gap by presenting agent based modelling as a tool to enable external stakeholders through mere observation, to estimate the risk of an illustrative company violating UK minimum-wage regulations. In this way, stakeholders may compare and contrast their own evaluation of business 
impacts on society with the information released by a company, if they are able to observe at least some of the company's activities.

The paper is structured as follows. After presenting the background to shadow accounting and the use of decision support systems for challenging corporate disclosure, we briefly discuss agent based models (ABMs) and then build a model of a manual car wash business to present the features of ABMs that may be useful for shadow accounting. We conclude the paper by discussing our findings and highlighting our contribution to the literature.

\section{Background}

Businesses are inclined towards narcissism in that they seek "admiration and recognition by highlighting their laudable achievements and camouflaging most of their negative impacts, which are likely to undermine the grandiose image that the reported information promotes" (Boiral, 2013, p.1043). Although these aims are entirely compatible with sustainable business practices (Brown and Fraser, 2006) they are distinctly incompatible with objective standards of reporting quality namely balance, completeness, accuracy and reliability (Boiral, 2013). Gold et al. (2016) conclude from an analysis of corporate reports in the agrifood sector that businesses tend to concentrate reporting on performance dimensions that are difficult to verify by consumers, in particular, sustainability. Similarly, Comyns and Figge (2015) have found through content analysis of greenhouse gas reporting in the oil and gas sector that the 'experience' and 'credence' information provided in sustainability reports (Comyns et al., 2013) is of low quality even though the percentage of firms reporting increased sharply during the period of the study. This evidence suggests that businesses leverage the elusiveness of many sustain-ability issues and exploit information asymmetries to the detriment of the consumer and stakeholder side.

Referring to the notion of the market for lemons from Akerlof (1970), companies taking advantage of the existing information asymmetry undermine the credibility of corporate reports on sustainability for stakeholders. By reporting only positive information, reports lose their quality meaning that they are not valued yet costly. Eventually this causes a shutdown in the market for information on corporate sustainability (Comyns et al., 2013) resulting in sustainability information becoming valueless (cf. Guiso et al., 2015). Summing up our arguments we may note at the most conceptual level that information asymmetries inhibit the efficient allocation of resources among economic actors thus impeding the overall maximisation of social welfare. 
To mitigate this information asymmetry, it seems important to promote shadow accounting from its niche existence tied to a few beacons such as Traidcraft (Dey, 2007b), Friends of the Earth (Dey, 2007a) and Corporate Watch (Gallhofer et al., 2006) to widespread and dependable alternative sources of information about businesses. However shadow accounting tends to fight an up-hill battle. Especially in areas such as corporate sustainability reporting, companies are trying to appropriate it for its own purpose (Gallhofer et al., 2006). Thus, shadow accounting struggles to serve its democratic function of offering alternative perspectives and alternative voices for holding powerful institutions accountable for their actions (Gray et al., 2014). Moerman and van der Laan (2015) suggest that shadow accounting can challenge corporate accounting and communication by addressing 1) the mismatch between policies and actual conduct, 2) the mismatch between disclosures by companies and those by external third parties, 3) deceitfulness and retention of information, and 4) secrecy regarding corporate decisions and their likely future impacts.

Despite several attempts in the last fifty years and an array of potential benefits, shadow accounting has largely remained "patchy, ad hoc, and unsystematic" (Gray et al., 2014, p.253) largely owing to lack of resources and insufficient backing from the scientific community. Early proponents such as the Counter Information Services (CIS) were distinctively radical. CIS were a group of Marxist journalists that published alternative accounts on a number of corporations including Ford and Unilever that were mainly based on information from mainstream media (Gray et al., 2014; Moerman and van der Laan, 2015). Although there have been a few academically driven shadow accounting projects such as the silent reports from the Centre for Social and Environmental Accounting Research on Tesco (Gibson et al., 2001; Adams, 2004), shadow accounting has not yet received sufficient academic support to fully develop its potential for society. Shadow accounting could strongly profit from innovative methods that help make sense of externally accessible information to challenge corporate speech.

So far decision support systems in this area have mainly been deployed in the detection of fraud in financial accounting and transactions. Glancy and Yadav (2011) for example, have proposed a computational screening model for detecting fraud in financial reporting; Humpherys et al. (2011) use linguistic credibility analysis for a similar purpose; Fuller et al. (2009) use linguistic analysis for detecting the risk of fraud in financial disclosure. More recently, Throckmorton et al. (2015) suggest that financial fraud detection tools may be enhanced by concurrently considering vocal, linguistic and financial cues. Focussing on the vocal cues of manager narratives, Larcker and Zakolyukina (2012) analysed the lin- 
guistic features of senior managements' presentations during quarterly earnings conference calls to detect the likelihood of financial statements being manipulated, under the assumption that senior managers have knowledge of such manipulations. Burgoon et al. (2015) confirmed the usefulness of linguistic analysis tools for examining management utterances during earnings conference calls, and specifically underline the importance of unscripted responses. On a slightly different but related note, decision support systems based on data mining have been deployed for detecting credit card fraud, a crime which causes huge damage to business and society and which represents a significant concern for consumers (e.g., Ngai et al. (2011); Bhattacharyya et al. (2011); Bahnsen et al. (2016)); it has also been used to uncover instances of money laundering (Gao and $\mathrm{Xu}, 2009)$.

While these examples show that there are a variety of decision support systems for scrutinising corporate financial accounts, no decision system for the analysis of social and environmental accounts can be found in the literature. This is not too surprising since financial accounting is in most countries embedded in a strong taxation and legal framework which specifies formal standards for auditing and assurance (Khalil et al., 2015). Failure to operate within this framework leads to litigation and this imposes real monetary costs on misstatements by management (Willekens and Simunic, 2007). In contrast, sustainability reporting remains largely a voluntary activity (Unerman and O'Dwyer, 2007).

Therefore new ways of shadow accounting to narrow the credibility gap should be explored. In particular, the social dimensions of sustainability - working conditions, labour rights and community well-being - have been largely neglected in modelling approaches (Seuring, 2013). Agent based modelling has already proved its suitability to investigate the social side of business and technical systems (e.g., Wu et al. (2015)). Agent based modelling is especially suitable as a decision support system for examining the social claims of businesses, thus backing shadow accounting endeavours.

Although there is a substantial and ongoing academic debate about how to deploy decision support systems for detecting fraud in financial accounting and transactions - in Decision Support Systems and other relevant journals - there is a striking dearth of literature on their use for scrutinising social and sustainability accounts, business reports, and business actions. On the other hand, the accounting and accountability literature features a lack of structured academic methods for verifying accounts that could mitigate the currently patchy and unsystematic nature of shadow accounting. This is despite a strong academic conversation on the shortcomings of corporately dominated accounts (Michelon et al., 2015) and the importance of shadow accounting and counter accounting. We contribute to 
this by proposing $\mathrm{ABMs}$ as an innovative and versatile method for facilitating shadow accounting based on externally accessible information that helps stakeholders to challenge business rhetoric and action, and hence create the 'cognitive dissonance' (Adams and Whelan, 2009) necessary for change towards business conduct that is better aligned with societal needs and preferences.

\section{Agent based modelling}

We propose that agent based modelling can be a useful tool for shadow accounting. An agent based model is a representation of a phenomenon or system, built from the interactions and behaviour of autonomous units or agents. They are well known (Heath et al., 2009) but in brief: typically an ABM is a computer simulation, a set of duplicate packets of software code that process and respond to signals from other packets of code. The packets are the agents which are instantiated to have certain attributes and then allowed to interact with each other in order to study the behavior that emerges. ABMs have successfully been used to study the swarming behaviour of birds and insects, the movements of molecules and other atomic particles under a range of conditions, climate change, the spread of fire, coastal erosion and a broad range of other phenomena. The use of agent based models in the social sciences is not common but is established (Borrill and Tesfatsion, 2011; Van Hemel et al., 2008; Bainbridge, 2006; Gilbert and Troitzsch, 2005) and has been used before in the study of decision support (Chesney, 2014; Lovric et al., 2013; Zaffar et al., 2011; Schramm et al., 2010; Macy and Willer, 2002). A robust philosophy of simulation exists (Winsberg, 2010). Economics in particular has embraced agent based modelling and has described it as a 'culture-dish approach to the study of economic worlds' (LeBaron and Tesfatsion, 2008). In a well known exploration of the possibilities, Epstein and Axtell (1996) create an ABM of social structures in society built up from the interactions of individuals to show the emergence of group formation, trade and combat. Van Hemel et al. (2008) review the use of ABMs in military research. A common criticism of ABMs is that they overly simplify a complex situation (Louie and Carley, 2008), although we note that in fact, any social science methodology could be accused of doing the same.

\section{Car wash case}

\subsection{Rationale}

In an almost throw-away line during a recent documentary (BBC Media Centre, 2016) an interviewee asks viewers to think about their spending habits and 
consider that 5 people working on washing a car for 20 minutes with a total payment of $£ 5$ must involve them being paid less than the minimum wage (of around $£ 7$ per hour). An ABM can examine this claim, easily incorporating elements that other approaches such as spreadsheet models and systems dynamics would find challenging. Broadly there are two ways we can use an ABM for shadow accounting in this case and these involve either working forwards or backwards. Working forwards we can set model parameters after having observed the car wash for a time, to determine what revenue it generates. Working backwards we can run the model multiple times, each time varying parameter values to examine the points at which the wash generates enough revenue to pay minimum wage, and then ask whether these values are plausible.

\subsection{The model}

A real car wash was chosen as the basis for the model. There are two parts to the wash. When a car enters, it joins or forms a queue. After a wash the customer can pay $£ 4$ and leave or can opt for a valet service (wax and vacuum for $£ 10$ ). There are $n$ workers at the car wash with typically $\boldsymbol{n}=[3,5]$ and this changes throughout the day with $n=2$ when the business opens each day. We assume that there are always enough workers, either through the existing workers being unable to move because of a lack of opportunities, or from a large pool of potential workers who are ready to replace any that move. Each area is worked on by two people if they are available with others choosing (seemingly at random) an activity to contribute to. As it happens, there are two government vehicle count points on the stretch of road where the car wash sits showing an average of nearly 20,000 cars passing each day (Department for Transport, 2014). The Government has also compiled statistics on the flow of traffic on the road throughout the day and these are shown in Figure 1.

[Figure 1 about here.]

The car wash has fixed costs. We investigated these and estimate that they are between $£ 200$ to $£ 500$ per week for rent, water fees, electricity and council tax. For our model we take a median figure of $£ 350$, but we also look at what would happen using the minimum and maximum figures. The wash opens seven days a week.

The simulation progresses in discrete time periods representing one second. During each, there is a probability that a car will drive past. In fact, there are two probabilities and they are time dependent: one for rush hour traffic prush $_{\text {and one }}$ 
for other times pnorm. Figure 1 is roughly bi-modal and roughly uniform between the two peaks. We used it to estimate that $53 \%$ of the daily 20,000 cars passes the car wash during open hours, and $20 \%$ of that is rush hour traffic (note that the car wash opens at 9am and is therefore closed for all but the tail end of the morning rush hour).

As each car passes the wash there is a probability $p_{w}$ that it will enter the wash. There is a probability $p_{v}$ that after a quick wash the customer will want a valet. Each car (the cars are the agents in the model) has two variables: $w$ stores how many seconds it will take to wash and $v$ stores how long it will take to valet, and these can vary to capture different sizes of vehicle on the road. Once a car is in a queue, any workers working on it will reduce $w$ or $v$ by 1 for each passing time period. If a driver approaches but sees a queue they may decide not to turn in. In this way, the ABM captures all the salient elements of the wash. A screen shot of the model is shown in Figure 2.

From our observations, a wash takes an average of 525 person-seconds ${ }^{1}$, a valet a further 1,750 person-seconds. The queue never grew longer than five cars with drivers tending to turn away where there are three or more cars ahead of them.

[Figure 2 about here.]

\subsection{Analysis}

In Section 4.1 we listed two ways of using an ABM as a shadow account for the car wash. Working forwards, we ran the model using the parameter values that we observed along with the publicly available data. This suggests that in a single day the wash would generate about $£ 500$ ( $£ 494$ ), minus fixed costs giving $£ 444$.

The second approach, working backwards, is to examine a range of values to determine the points at which a minimum level of revenue is generated, and then asking whether these values are realistic. Taking the probability $p_{w}$, Figure 3 shows the revenue generated when varying $p_{w}$ for three levels of $n$ during one hour in non-rush hour traffic. The horizontal line shows the minimum needed to generate sufficient earnings for the wash to pay its workers minimum wage. At around $p=0.005$ the car wash becomes profitable. Feeding this figure into the $\mathrm{ABM}$ causes just over 40 cars to go to the wash each day which seems realistic.

1This means 1 person could complete a wash in 525 seconds; 3 could do it in 175 , 10 could do it in 53. 
[Figure 3 about here.]

While $p_{w}=0.005$ seems realistic, we dropped this figure to see how high $p_{v}$ would have to be for the car wash to stay profitable. At $p_{w}=0.001$ the car wash was not profitable with any number of workers. At $n=5$ and $p_{w}=0.002$ the wash was not profitable. With $n=5$ and $p_{w}=0.004$ the car wash was profitable if $p_{v}=$ 0.6 (the value we observed was 0.5 so again this seems at least plausible).

In terms of the legality of the car wash then, the ABM gives the following results: $£ 444$ is enough to pay minimum wage and 40 + cars per day is a figure which certainly intuitively seems possible. Contrary to what the BBC documentary suggested, our car wash does appear to be able to produce enough money to operate legally, even if we factor in the highest figure for fixed costs.

(As an aside, we note that by examining the company accounts, we could work backwards to determine whether the firm's claim that it is paying minimum wage is plausible. This could also potentially be used to detect fraudulent behaviour such as money laundering. The accounts of the car wash will be publicly available but we have not accessed them as in this instance our interest is not in fraud. It is important again to emphasise that our car wash example is illustrative and we do not suspect it of any illegal behaviour.)

\section{Discussion}

Our ABM suggests that this particular car wash is making enough money to pay its employees a minimum wage. We stress again that our illustration cannot and could not provide a proof of wage abuses in a strict sense: Just because a company earns enough to pay minimum wage does not mean that it does so. Similarly, just because it does not earn enough, does not mean staffaren't being paid properly: Some business owners accept operating at a loss, for instance if the business is conceived as a hobby activity. We should also stress that in the case of the car wash, if insufficient revenue was being generated and workers were being paid less than minimum, it does not necessarily mean laws are being broken as is possible to employ workers as contractors working on a commission per vehicle.

Instead, rather than providing any sort of proof, agent based modelling facilitates shadow accounting through its potential to indicate discrepancies between conduct published in company accounts and actual conduct based on independently observed empirical data. In this way, the method we are proposing could be used to give an indication of various forms of fraud and unethical business 
conduct. Taken further, ABMs may inform the development of a group of computational screening models that go beyond the detection of fraud in financial reporting, towards the detection of fraud and deception in broader social aspects of business.

The car wash ABM was not difficult to create and after observing the operation of the business, it only took an afternoon to implement. Someone with an interest in shadow accounting could learn to produce an ABM using modern tools, facing a learning curve that is perhaps only marginally steeper than that faced when learning to use a traditional accounting package. In fact the actual observation itself might be the most challenging part of shadow accounting and we note that our choice of case is one that is easily observed; this would not be so for many businesses where workers are for example in different countries, enclosed behind factory gates or as domestic workers behind closed doors. In the case of the car wash where it is easy to observe production activities and service delivery but difficult to draw robust conclusions from these observations, the use of $\mathrm{ABM}$ can be seen as an important instrument for shadow accounting. One may argue that consumers are increasingly in charge of flagging alleged cases of labour exploitation if production activities and service delivery are clearly visible to them. These suspected cases may then be taken up and scrutinized by actors that are skilled in using ABM modelling.

Our results suggest that there is a place for ABMs that use empirical observations to provide a decision support tool for verifying corporate sustainability communications and scrutinising corporate action (Balineau and Dufeu, 2010), thereby helping to mitigate information asymmetries that are currently disadvantaging consumers and stakeholders (Gold et al., 2016). ABMs empower stakeholders to actively fulfil their watchdog function (Heikkurinen and Ketola, 2012), and might even be useful for raising initial suspicion on the part of state authorities regarding criminal offences such as money laundering (cf. Gao and $\mathrm{Xu}, 2009$ ) or slavery (cf. Gold et al., 2015). In this way, they represent a potentially powerful tool for shadow accounting (Rodrigue, 2014) that warrants further academic exploration and practical application. As illustrated in this paper, there is good reason to believe that ABMs may help to emancipate stakeholders from the tutelage and secrecy of business (Spence, 2009), and may strengthen the voice of societal stakeholders at the business-society interface thus providing an arena for a more cacophonic, equal, and democratic discourse about business conduct and the responsibilities of business towards society at large (Gray et al., 2014). In today's world of 'big data', ABM may capitalize on decreasing costs of data production and dissemination thus reducing information asymmetries among societal actors 
and ultimately improving social welfare. In the case of the car wash for example, data from satellites could be used for shadow accounting. Satellites tracking the fill rate of parking lots are already used by financial analysts to predict sales and hence create a shadow account of revenues of shopping malls (Balakrishnan, 2016).

Summing up, ABM represents a systematic and reliable procedure for creating robust shadow accounts if labour and other aspects of production and service can be observed by stakeholders but these data cannot be easily evaluated.

\section{Conclusions}

This paper advocates the use of ABMs as a tool for facilitating and enhancing the impact of shadow accounting. At the same time we acknowledge that our approach, and its presentation in this paper, does not go without limitations. First of all, production activities and service delivery need to be at least partly observable to generate sufficient data to base the ABM on. This is often not the case when workers are in remote countries, in private domestic settings, or in fenced-off factories. Even if some observability is given, there is still the human factor of indifference that hinders endeavours of shadow accounting as by far not all stakeholders are willing to get involved, raise concerns, and share their observations with people skilled in ABM. Furthermore, we have repeatedly emphasized that ABMs and shadow accounting more generally, have to be applied with caution so to make them tools for holding business accountable for their actions, rather than creating a destructive culture of suspicion within society.

The paper extends the current academic debate about how to use decision support systems for detecting fraud and inconsistencies in financial accounting and transactions (e.g. Throckmorton et al., 2015; Burgoon et al., 2015; Bahnsen et al., 2016) towards investigating and scrutinizing corporate sustainability accounting, communication, and actions. In this way, it sheds light on a so far largely neglected

area of research. At the same time our approach shows one promising avenue of how the currently patchy and unsystematic nature of shadow accounting (Gray et al., 2014) could be replaced by more structured approaches. By proposing ABMs as an innovative and versatile method for facilitating shadow accounting based on externally accessible information, our paper contributes to the literature streams on decision support systems as well as on sustainability accounting and reporting. By increasing opportunities to scrutinize and challenge corporate rhetoric and action, the current 'corporate domination of sustainabil-ity accounting' (Michelon et al., 2015) can be broken up. Consequently, ABMs 
may be seen as important tools for generating 'cognitive dissonance' (Adams and Whelan, 2009) that makes business strategically and comprehensively incorporate societal needs and preferences. Hence, ABMs could strengthen the so far largely neglected social dimension when modelling sustainability in business. Their use would meet for example the resonating call in Decision Support System by Seuring (2013) to increasingly base modelling approaches in sustainability management on empirical data. They also represent an opportunity for interdisciplinary research when those with knowledge of agent modelling can partner with those with a desire to investigate practices in different industries.

Agent-based modelling is certainly not the only method of modelling our example of the car wash, but it comes with particular strengths that make it suitable for wider use in the field of social and financial accounting and accountability. Unlike systems dynamics, ABMs are particularly suited to handling various forms of heterogeneity: different sizes of vehicle, peak days and months through the year and workers of different abilities taking breaks of different length throughout the day. ABMs allow for more dynamic interactions of agents and more complex recursive reasoning processes. Each parameter in a model can be varied and repeated many thousands of times, and scenarios can be compared. All of this can be done from the computer as soon as any observation of the business is complete. ABMs will show at what point enough money is being made by a firm for it to be able to pay the minimum wage and they can verify other aspects of social and financial accounting. We repeat our call that the use of ABMs as a tool for shadow accounting warrants further academic exploration and practical application.

\section{Acknowledgements}

The agent model was developed using the Netlogo platform by Uri Wilensky (https://ccl.northwestern.edu/netlogo). We also acknowledge help from Nottinghamshire Police in advising on the car wash case. 


\section{References}

Adams, C. A., 2004. The ethical, social and environmental reportingperformance portrayal gap. Accounting, Auditing \& Accountability Journal 17 (5), 731- 757.

Adams, C. A., Whelan, G., 2009. Conceptualising future change in corporate sus-tainability reporting. Accounting, Auditing \& Accountability Journal 22 (1), 118-143.

Akerlof, G., 1970. The market for "lemons": Quality uncertainty and the market mechanism. Quarterly Journal of Economics 84 (3), 488-500.

Bahnsen, A. C., Aouada, D., Stojanovic, A., Ottersten, B., 2016. Feature engineering strategies for credit card fraud detection. Expert Systems with Applications.

Bainbridge, W. S., 2006. God from the machine. AltaMira Press.

Balakrishnan, A., 2016. Fewer cars are parked at malls. here's what that could mean for apple, analyst says. CNBC.

URL http://www.cnbc.com/2016/12/09/fewer-cars-are-parked-at-malls-heres-what

Balineau, G., Dufeu, I., 2010. Are fair trade goods credence goods? a new proposal, with french illustrations. Journal of Business Ethics 92 (2), 331-345.

BBC Media Centre, 2016. Britain's secret slavery business.

URL http://www.b.bc.co.uk/mediacentre/proginfo/2016/10/britains-secret-slaver

Bhattacharyya, S., Jha, S., Tharakunnel, K., Westland, J. C., 2011. Data mining for credit card fraud: A comparative study. Decision Support Systems 50 (3), 602-613.

Boiral, O., 2013. Sustainability reports as simulacra? a counter-account of a and at gri reports. Accounting, Auditing \& Accountability Journal 26 (7), 1036- 1071.

Borrill, P. L., Tesfatsion, L., 2011. 11 agent-based modeling: the right mathematics for the social sciences? The Elgar companion to recent economic methodology 228. 
Brown, J., Fraser, M., 2006. Approaches and perspectives in social and environmental accounting: an overview of the conceptual landscape. Business Strategy and the Environment 15 (2), 103-117.

Burgoon, J., Mayew, W. J., Giboney, J. S., Elkins, A. C., Moffitt, K., Dorn, B., Byrd, M., Spitzley, L., 2015. Which spoken language markers identify deception in high-stakes settings? evidence from earnings conference calls. Journal of Language and Social Psychology, 0261927X15586792.

Chesney, T., 2014. Networked individuals predict a community wide outcome from their local information. Decision Support Systems 57, 11-21.

Comyns, B., Figge, F., 2015. Greenhouse gas reporting quality in the oil and gas industry: A longitudinal study using the typology of "search" "experience" and "credence" information. Accounting, Auditing \& Accountability Journal 28 (3), 403-433.

Comyns, B., Figge, F., Hahn, T., Barkemeyer, R., 2013. Sustainability reporting: The role of "search", "experience" and "credence" information. In: Accounting Forum. Vol. 37. Elsevier, pp. 231-243.

Department for Transport, 2014. Traffic counts. URL http: / /www.dft.gov.uk/traffic-counts/

Dey, C., 2007a. Developing silent and shadow accounts. Sustainability accounting and accountability, 307-326.

Dey, C., 2007b. Social accounting at traidcraft plc: A struggle for the meaning of fair trade. Accounting, Auditing \& Accountability Journal 20 (3), 423-445.

Dingwerth, K., Eichinger, M., 2010. Tamed transparency: How information disclosure under the global reporting initiative fails to empower. Global Environmental Politics 10 (3), 74-96.

Epstein, J., Axtell, R., 1996. Growing artificial societies. Brookings Institution Press.

Fuller, C. M., Biros, D. P., Wilson, R. L., 2009. Decision support for determining veracity via linguistic-based cues. Decision Support Systems 46 (3), 695703. 
Gallhofer, S., Haslam, J., Gallhofer, S., Haslam, J., Monk, E., Roberts, C., 2006. The emancipatory potential of online reporting: the case of counter accounting. Accounting, Auditing \& Accountability Journal 19 (5), 681-718.

Gao, S., Xu, D., 2009. Conceptual modeling and development of an intelligent agent-assisted decision support system for anti-money laundering. Expert Systems with Applications 36 (2), 1493-1504.

Gibson, K., Gray, R., Laing, Y., Dey, C., 2001. The silent accounts project: Draft silent and shadow accounts 1999-2000 for tesco plc. Centre for Social \& Environmental Accounting Research: Glasgow.

Gilbert, N., Troitzsch, K., 2005. Simulation for the social scientist second edition. Open University Press.

Glancy, F. H., Yadav, S. B., 2011. A computational model for financial reporting fraud detection. Decision Support Systems 50 (3), 595-601.

Gold, S., Kunz, N., Reiner, G., 2016. Sustainable global agrifood supply chains: Exploring the barriers. Journal of Industrial Ecology.

Gold, S., Trautrims, A., Trodd, Z., 2015. Modern slavery challenges to supply chain management. Supply Chain Management: An International Journal 20 (5), 485-494.

Gov.UK, 2014. Traffic flows by time and day. URLhttps://www.gov.uk/government/uploads/system/uploads/attachment data/fil

Gray, R., Adams, C., Owen, D., 2014. Accountability, social responsibility and sustainability: Accounting for society and the environment. Pearson Higher Ed.

Guillamon-Saorin, E., Osma, B. G., Jones, M. J., 2012. Opportunistic disclosure in press release headlines. Accounting and Business Research 42 (2), 143168.

Guiso, L., Sapienza, P., Zingales, L., 2015. The value of corporate culture. Journal of Financial Economics 117 (1), 60-76.

Heath, B., Hill, R., Ciarallo, F., 2009. A survey of agent-based modeling practices (january 1998 to july 2008). Journal of Artificial Societies and Social Simulation 12 (4), 9. 
Heikkurinen, P., Ketola, T., 2012. Corporate responsibility and identity: from a stakeholder to an awareness approach. Business Strategy and the Environment 21 (5), 326-337.

Humpherys, S. L., Moffitt, K. C., Burns, M. B., Burgoon, J. K., Felix, W. F., 2011. Identification of fraudulent financial statements using linguistic credibility analysis. Decision Support Systems 50 (3), 585-594.

Junior, R. M., Best, P. J., Cotter, J., 2014. Sustainability reporting and assurance: a historical analysis on a world-wide phenomenon. Journal of Business Ethics 120 (1), 1-11.

Khalil, S., Saffar, W., Trabelsi, S., 2015. Disclosure standards, auditing infrastructure, and bribery mitigation. Journal of Business Ethics 132 (2), 379-399.

Knebel, S., Seele, P., 2015. Quo vadis gri? a (critical) assessment of gri $3.1 \mathrm{a}+$ non-financial reports and implications for credibility and standardization. Corporate Communications: An International Journal 20 (2), 196-212.

Larcker, D. F., Zakolyukina, A. A., 2012. Detecting deceptive discussions in conference calls. Journal of Accounting Research 50 (2), 495-540.

LeBaron, B., Tesfatsion, L., 2008. Modeling macroeconomies as open-ended dynamic systems of interacting agents. The American Economic Review 98 (2), 246-250.

Louie, M. A., Carley, K. M., 2008. Balancing the criticisms: Validating multiagent models of social systems. Simulation Modelling Practice and Theory $16(2), 242-256$.

Lovric, M., Li, T., Vervest, P., 2013. Sustainable revenue management: A smart card enabled agent-based modeling approach. Decision Support Systems 54 (4), 1587-1601.

Macy, M. W., Willer, R., 2002. From factors to actors: Computational sociology and agent-based modeling. Annual review of sociology, 143-166.

Merkl-Davies, D. M., Brennan, N. M., McLeay, S. J., 2011. Impression management and retrospective sense-making in corporate narratives: A social psychology perspective. Accounting, Auditing \& Accountability Journal 24 (3), 315-344. 
Michelon, G., Pilonato, S., Ricceri, F., 2015. CSR reporting practices and the quality of disclosure: An empirical analysis. Critical Perspectives on Accounting 33, 59-78.

URL http://www.sciencedirect.com/science/article/pii/S1045235414001051

Moerman, L., van der Laan, S., 2015. Exploring shadow accountability: The case of james hardie and asbestos. Social and Environmental Accountability Journal 35 (1), 32-48.

Ngai, E., Hu, Y., Wong, Y., Chen, Y., Sun, X., 2011. The application of data mining techniques in financial fraud detection: A classification framework and an academic review of literature. Decision Support Systems 50 (3), $559-569$.

O’Sullivan, N., O’Dwyer, B., 2009. Stakeholder perspectives on a financial sector legitimation process: The case of ngos and the equator principles. Accounting, Auditing \& Accountability Journal 22 (4), 553-587.

Owen, D. L., Swift, T., Hunt, K., 2001. Questioning the role of stakeholder engagement in social and ethical accounting, auditing and reporting. In: Accounting forum. Vol. 25. Wiley Online Library, pp. 264-282.

Reimsbach, D., Hahn, R., 2015. The effects of negative incidents in sustainability reporting on investors' judgments-an experimental study of third-party versus self-disclosure in the realm of sustainable development. Business Strategy and the Environment 24 (4), 217-235.

Rodrigue, M., 2014. Contrasting realities: corporate environmental disclosure and stakeholder-released information. Accounting, Auditing \& Accountability Journal 27 (1), 119-149.

Schramm, M. E., Trainor, K. J., Shanker, M., Hu, M. Y., 2010. An agent-based diffusion model with consumer and brand agents. Decision Support Systems 50 (1), 234-242.

Seuring, S., 2013. A review of modeling approaches for sustainable supply chain management. Decision Support Systems 54 (4), 1513-1520.

Spence, C., 2009. Social accounting's emancipatory potential: A gramscian critique. Critical Perspectives on Accounting 20 (2), 205-227. 
Throckmorton, C. S., Mayew, W. J., Venkatachalam, M., Collins, L. M., 2015. Financial fraud detection using vocal, linguistic and financial cues. Decision Support Systems 74, 78-87.

Unerman, J., O'Dwyer, B., 2007. The business case for regulation of corporate social responsibility and accountability. In: Accounting Forum. Vol. 31. Elsevier, pp. 332-353.

Van Hemel, S. B., MacMillan, J., Zacharias, G. L., et al., 2008. Behavioral Modeling and Simulation:: From Individuals to Societies. National Academies Press.

Willekens, M., Simunic, D. A., 2007. Precision in auditing standards: Effects on auditor and director liability and the supply and demand for audit services. Accounting and Business research 37 (3), 217-232.

Winsberg, E., 2010. Science in the age of computer simulation. University of Chicago Press.

Wu, P. P.-Y., Fookes, C., Pitchforth, J., Mengersen, K., 2015. A framework for model integration and holistic modelling of socio-technical systems. Decision Support Systems 71, 14-27.

Zaffar, M. A., Kumar, R. L., Zhao, K., 2011. Diffusion dynamics of open source software: An agent-based computational economics (ace) approach. Decision Support Systems 51 (3), 597-608. 


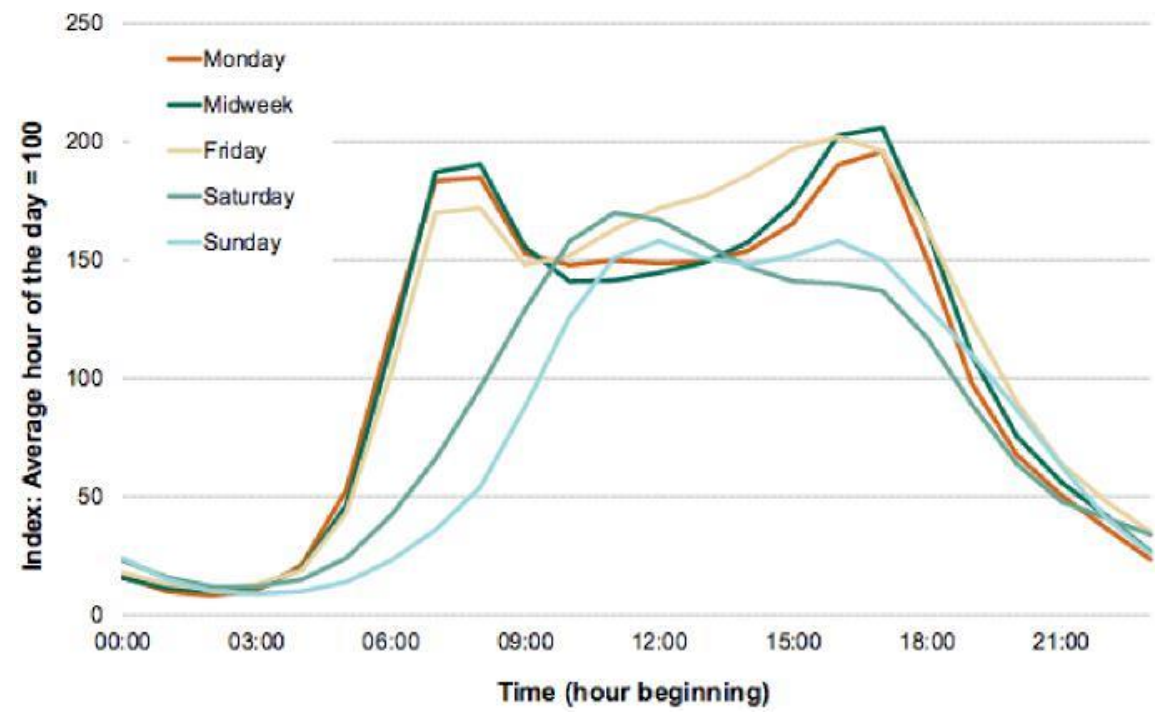

Figure 1: Distribution of traffic flows by time of day and day of the week in the UK in 2014. The $y$-axis measure is normalised to give a unitless average of 100 and this allows an estimation of how the 20,000 cars passing the car wash will be distributed throughout the day. Source: Gov.UK (2014) 


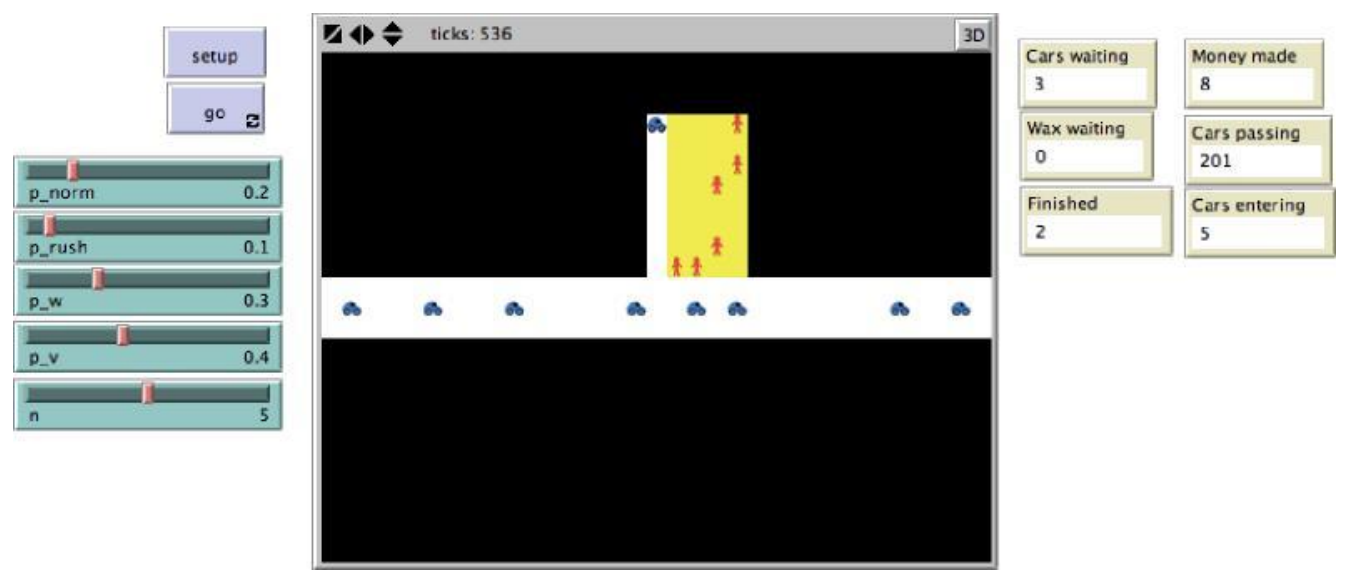

Figure 2: The initial model. Cars pass the car wash (the central area) and enter with a certain probability for a quick wash (the queue is shown on the left of the central area). Afterwards they may stay for a valet (shown here to the right of the central area). 

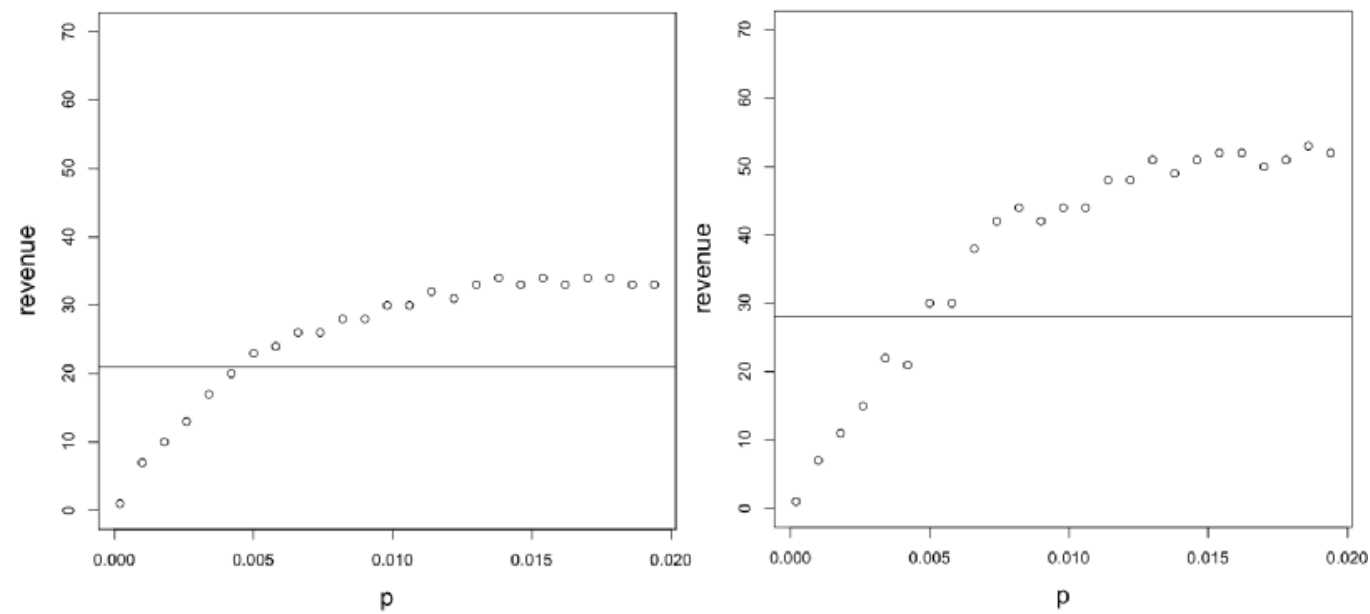
(a) $n=5$
(b) $n=4$

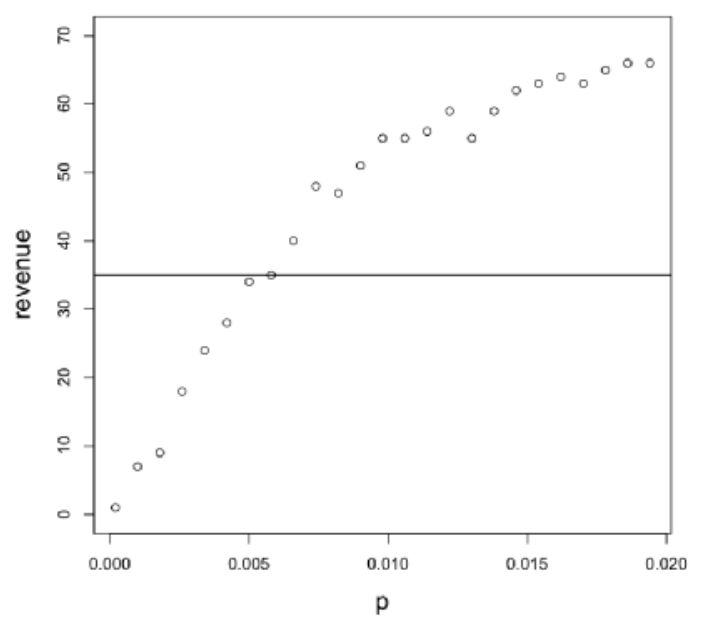

(c) $n=3$

Figure 3: The three panels show the revenue generated when varying the probability $p_{w}$ that a passing car will enter the car wash for three levels of $n$ during one hour of non-rush hour traffic. The horizontal line shows the minimum needed to generate sufficient revenue to pay minimum wage. 